\title{
Prediction of Major Adverse Cardiac Events of Patients with Acute Coronary Syndrome by Using TIMI Risk Score
}

\author{
MOHAMMAD ABUL EHSAN, MANZOOR MAHMOOD, MD ABU SIDDIQUE, SAJAL KRISHNA BANERJEE, \\ LAILA FARZANA KHAN, ATM IQBAL HASAN, MD. ABU SALIM, MD ASHRAF UDDIN SULTAN \\ Department of Cardiology, Bangabandhu Sheikh Mujib Medical University (BSMMU), Dhaka \\ Address for Correspondance: Dr. Mohammad Abul Ehsan, Department of Cardiology, Bangabandhu Sheikh Mujib Medical \\ University, Dhaka, E-mail: ehsans91@yahoo.com
}

\begin{abstract}
:
Background: Patient with acute coronary syndrome (ACS) has considerable variability in outcome and mortality risk. The Thrombolysis in Myocardial Infarction (TIMI) risk score for unstable angina/non ST elevation myocardial infarction \& ST elevation myocardial infarction were a convenient bedside clinical risk score for predicting 30 days mortality at presentation with ACS. Aim \& objectives: This study was done to predict and validate major adverse cardiac events in patients of ACS thus it will help us to quantify risk, observe the prognostic value and to guide appropriate therapy by using TIMI risk score. Methods: This prospective study was carried out in the department of cardiology, BSMMU, Dhaka from April, 2011 to March, 2012. After considering all ethical issues, data were collected from 279 patients attending at cardiac emergency department with the presentation of ACS. History \& complete physical examinations were done. ST changes in electrocardiogram \& CKMB/Troponin value were noted in data sheet. TIMI risk score was calculated for each patient. The major adverse cardiac events (recurrent myocardial infarction, urgent revascularization, and all-cause mortality) were measured for next 30 days in hospital setting \& outpatient department by follow up. After follow-up, Cox univariate and multivariate regression analysis were used to evaluate the influence of potential risk factors on duration of event-free survival, and likelihood ratio tests to assess the outcome. Results: In patient with UA/NSTEMI major adverse cardiac events were 0\%, $4.2 \%$, 6.9\%, 12.5\%, 13.6\% and 33.3\% with TIMI score $0 / 1,2,3,4,5$ and $6 / 7$ respectively. . In patients with STEMI group major adverse cardiac events were $0 \%, 0 \%, 0 \%, 0 \%, 7.1 \%, 9.5 \%, 10 \%, 17.6 \%, 19 \%$ and 38.5\% with TIMI score 0, 1, 2, 3, 4, 5, 6, 7, 8 and more than 8 respectively. Conclusions: Increasing TIMI risk score was associated with increased risk of major adverse cardiac events. These score were a valid tool for risk assessment.
\end{abstract}

Introduction:

Acute coronary syndrome (ACS) includes unstable angina (UA), non ST- elevation myocardial infarction (NSTEMI) and ST-elevation myocardial infarction (STEMI). All three conditions share a common pathophysiology, characterized by acute coronary insufficiency due to disruption of a vulnerable plaque with superadded thrombus formation with or without vasospasm following rupture of atheromatous plaque. By the year 2020 it is estimated that it will be the major cause of death in all regions of the world and will hold the first place in the World Health Organization's list of leading cause of disability. Coronary artery disease has been recognized as one of the leading cause of death in our country. Prevalence of IHD in urban population of Bangladesh was 100 per thousand. In another survey, it was found that IHD accounts for about $18 \%$ of cardiac admission in a general hospital ${ }^{1}$. Hospital mortality in case of AMI is low in young patients with subendocardial infarct without circulatory disturbance and conversely, mortality is high in case of cardiogenic shock in all age groups. Between these two extremes, prognosis varies widely ${ }^{2}$. Patient presenting with NSTEMI have an intermediate risk of acute complications when compared with patients with unstable angina (lower risk) and lower risk when compared with STEMI ${ }^{3}$. Because of the life-threatening nature, risk stratification of a patient with ACS can provide an estimate of a patient's optimal clinical choices. Simple clinical indicators of risk include hypotension, cardiac failure and ventricular arrhythmias. More detailed risk stratification can be made by using the Thrombolysis In Myocardial Infarction risk score 
(TIMI) or Global Registry of Acute Coronary Events scores (GRACE). The TIMI risk score was derived from patients recruited to randomized controlled trials of low molecular weight heparins ${ }^{4,5}$. The main advantages of this score are its simplicity and ease of use. The Thrombolysis In Myocardial Infarction (TIMI) risk score and TIMI risk index (TRI) helps to provide a more accurate assessment of a patient's prognosis. This information would be helpful for patients and their families and would also allow for more effective triaging and clinical allocation. So management of patients with an acute coronary syndrome requires accurate risk stratification to guide appropriate therapy ${ }^{6}$. Study showed that death rate, recurrent MI or urgent revascularization significantly increased when TIMI risk score increased, ranging from $<5 \%$ for patients with a risk score of 0 or 1 to $>40 \%$ for patients with a risk score 6 or 7 for NSTEMI. Trials have demonstrated the efficacy of new pharmacologic agents, such as low-molecular-weight heparins (LMWH), 7,8 and glycoprotein (GP) IIb/IIIa inhibitors and of an early invasive management strategy for ACS patients ${ }^{9}$. However, these treatment options are expensive and with risk of complications. Risk stratification can be used to identify patients who would derive particular benefit from these therapies. In particular, the capacity to reliably identify patient at very low risk for fatal recurrent events may offer the opportunity to select low risk patients for early discharge ${ }^{10}$. In the developing nations like South Asian countries, medical facilities are very limited and various investigation procedures are not widely available, very often costly and time consuming. In these situations TIMI risk score is likely to be clinically useful to predict the short term prognosis and help in planning in early management of patients and may also serve as a valuable aid in designing clinical research. In our country, however no such clinical prognostic tool has been developed or evaluated as yet. This study is designed to assess and develop a clinical bedside prognostic tool for risk assessment in ACS.

\section{Methods:}

Patients with a diagnosis of ACS attending cardiac emergency of BSMMU hospital taken as sample. The purpose of the study has been explained in details to each subject. Informed written consent and detailed history were taken. Clinical examination findings, demographic data and risk factor profile were noted. ECG and Troponin / CKMB were done and findings were noted. TIMI risk score was calculated for each patient. The main outcome of recurrent myocardial infarction, urgent revas- cularization, and all-cause mortality were recorded within 14 days and 30 days of follow up periods.

TIMI risk score for UA/NSTEMI

- age 65 years or more.

- chest pain in previous 24 hours and at least 2 or more episodes.

- three or more major risk factors (diabetes, hypertension, hypercholesterolemia, family history of IHD \& current smoker).

- aspirin in last 7 days.

- known coronary artery disease (cath stenosis $>50 \%$ ).

- ST segment deviation 0.5 mm or more on initial ECG.

- elevated CKMB/ troponin level.

Total score were 7 .

TIMI risk score for STEMI.

- age 75 years or more 3 points and 65-74 years 2 points.

- DM or HTN or angina 1 point.

- systolic blood pressure below 100 mm of Hg 3 points.

- heart rate more than 100/min 2 points.

- Killip class II-IV 2 points.

- weight less than $67 \mathrm{~kg} 1$ point.

- anterior MI or LBBB 1 point.

- time to treatment more than 4 hours 1 point.

Total score were 14 .

After follow-up, Cox univariate and multivariate regression analysis were used to evaluate the influence of potential risk factors. All data were analyzed by using SPSS (Statistical Package for Social Science) software version 16 for windows. Statistical significance of difference was analyzed with appropriate formula. P value of less than 0.05 was considered as significant

\section{Results:}

This was a prospective study conducted in Bangabandhu Sheikh Mujib Medical University, Dhaka. The main objective of the study was to predict, 30 days major adverse cardiac events by using TIMI risk score and TIMI risk index. A mid term major adverse events were also calculated at $14^{\text {th }}$ day. Total 279 patients of ACS were enrolled in the study. Of them 132 were UA/NSTEMI group and 147 were in STEMI group. The baseline characteristics of the study population and its prediction are presented in table I. 
Table-I

Patients baseline characterstics. $\quad(n=279)$

\begin{tabular}{|c|c|c|c|c|c|}
\hline \multirow[t]{2}{*}{ Variables } & \multicolumn{2}{|c|}{$\begin{array}{c}\text { UA/NSTEMI } \\
(\mathrm{n}=132)\end{array}$} & \multicolumn{2}{|c|}{$\begin{array}{l}\text { STEMI } \\
(n=147)\end{array}$} & \multirow[t]{2}{*}{ P value } \\
\hline & No. & $(\%)$ & No. & $(\%)$ & \\
\hline \multicolumn{6}{|l|}{ Age (years) } \\
\hline$<65$ & 64 & $(48.5)$ & 107 & (72.8) & $0.0001 * * *$ \\
\hline$\geq 65$ & 68 & $(51.5)$ & 40 & $(27.2)$ & \\
\hline Mean \pm SD & $62.24 \pm 7.67$ & & $58.73 \pm 9.55$ & & $0.001^{* *}$ \\
\hline Sex & & & & & $0.029 *$ \\
\hline Male & 92 & $(69.7)$ & 119 & $(81.0)$ & \\
\hline Female & 40 & (30.3) & 28 & $(19.0)$ & \\
\hline Weight (Kg) & & & & & $0.0001^{* * *}$ \\
\hline$<67$ & 122 & $(92.4)$ & 104 & $(70.7)$ & \\
\hline$\geq 67$ & 10 & $(7.6)$ & 43 & (29.3) & \\
\hline Mean \pm SD & $55.83 \pm 5.73$ & & $58.84 \pm 7.99$ & & $0.0001 * * *$ \\
\hline Chest pain & 125 & (94.7) & 147 & $(100)$ & $0.005^{* *}$ \\
\hline Shortness of breath & 14 & $(10.6)$ & 27 & (18.4) & $0.068 \mathrm{~ns}$ \\
\hline Collapse & 0 & $(0)$ & 4 & $(2.7)$ & $0.056 \mathrm{~ns}$ \\
\hline Palpitation & 2 & $(17.4)$ & 19 & (12.9) & $0.294 \mathrm{~ns}$ \\
\hline Autonomic symptoms & 7 & $(5.3)$ & 10 & $(6.8)$ & $0.601 \mathrm{~ns}$ \\
\hline $\begin{array}{l}\text { History of chest pain in last } \\
24 \text { hours ( } \geq 2 \text { episodes) }\end{array}$ & 74 & $(56.1)$ & 14 & (9.5) & $0.0001 * * *$ \\
\hline History of angina & 22 & $(16.6)$ & 12 & $(8.2)$ & $0.001 * *$ \\
\hline Known coronary disease & 5 & $(3.8)$ & 6 & $(4.1)$ & 0.900 ns \\
\hline $\begin{array}{l}\text { History of taking aspirin } \\
\text { in last } 7 \text { days }\end{array}$ & 47 & $(35.6)$ & 11 & (7.5) & $0.0001 * * *$ \\
\hline Current smoker & 48 & $(36.4)$ & 69 & $(46.9)$ & $0.074 \mathrm{~ns}$ \\
\hline Hypertension & 70 & $(53.0)$ & 53 & $(36.1)$ & $0.004^{* *}$ \\
\hline Diabetes & 36 & $(27.3)$ & 23 & $(15.6)$ & 0.018* \\
\hline Dyslipidemia & 99 & (75.3) & 68 & (46.3) & $0.0001 * * *$ \\
\hline Family history of IHD & 14 & $(10.6)$ & 21 & (14.3) & $0.354 \mathrm{~ns}$ \\
\hline 3 or more risk factors & 61 & $(46.2)$ & 124 & $(84.4)$ & $0.0001^{* * *}$ \\
\hline Pulse(b/min) & & & & & $0.0001 * * *$ \\
\hline$<100$ & 125 & $(94.7)$ & 96 & $(65.3)$ & \\
\hline$>100$ & 7 & $(5.3)$ & 51 & (34.7) & \\
\hline Mean \pm SD & $78.27 \pm 12.13$ & & $90.71 \pm 18.38$ & & $0.0001 * * *$ \\
\hline SBP(mm of Hg) & & & & & $0.002 * *$ \\
\hline$<100$ & 10 & $(7.6)$ & 30 & $(20.4)$ & \\
\hline$>100$ & 122 & $(92.4)$ & 117 & (79.6) & \\
\hline Mean \pm SD & $119.62 \pm 16.60$ & & $109.63 \pm 15.52$ & & $0.0001 * * *$ \\
\hline Killip class & & & & & $0.056 \mathrm{~ns}$ \\
\hline I & 117 & $(88.6)$ & 118 & (80.3) & \\
\hline II-IV & 15 & (11.4) & 29 & (19.7) & \\
\hline ST depression & 83 & (62.9) & - & - & \\
\hline \multicolumn{6}{|l|}{ ST elevation } \\
\hline Anterior & - & - & 103 & $(70.1)$ & \\
\hline Inferior & - & - & 44 & (29.9) & \\
\hline $\mathrm{T}$ inversion only & 34 & $(25.8)$ & - & - & \\
\hline RBBB only & 8 & $(6.1)$ & - & - & \\
\hline
\end{tabular}

Statistical analysis done by Chi- square test for categorical values and by unpaired Student's ' $t$ ' test for quantitative values. 
Table-II

Distribution of patients by major adverse cardiac events at $14 / 30$ days. $(n=279)$

\begin{tabular}{|c|c|c|c|c|c|}
\hline \multirow[t]{2}{*}{ Variables } & \multicolumn{2}{|c|}{$\begin{array}{c}\text { UA/NSTEMI } \\
(\mathrm{n}=132)\end{array}$} & \multicolumn{2}{|c|}{$\begin{array}{l}\text { STEMI } \\
(n=147)\end{array}$} & \multirow[t]{2}{*}{$P$ value } \\
\hline & No. & $(\%)$ & No. & $(\%)$ & \\
\hline Adverse events & 14 & $(10.6)$ & 17 & $(11.6)$ & $0.779 \mathrm{n}$ \\
\hline Death & 10 & $(7.5)$ & 17 & (11.6) & \\
\hline Recurrent MI & 2 & $(1.5)$ & 0 & $(0)$ & \\
\hline $\begin{array}{l}\text { Urgent } \\
\text { revascularization }\end{array}$ & 2 & $(1.5)$ & 0 & $(0)$ & \\
\hline
\end{tabular}

Statistical analysis done by Chi- square test.

Table-III

Univariate risk analysis of 30 days Major Adverse Cardiac Events of UA/NSTEMI. (n=279)

\begin{tabular}{|c|c|c|c|c|c|}
\hline \multirow[t]{2}{*}{ Parameters } & \multicolumn{2}{|c|}{$\begin{array}{c}\text { Overall } \\
(n=14)\end{array}$} & \multirow[t]{2}{*}{ OR } & \multirow[t]{2}{*}{$95 \% \mathrm{CI}$} & \multirow[t]{2}{*}{ P value } \\
\hline & No. & $\%$ & & & \\
\hline Age $\geq 65$ years & 11 & $(78.5)$ & 3.44 & $0.6-3.32$ & $0.0001 * * *$ \\
\hline Female & 3 & $(21.4)$ & 1.01 & $0.47-4.57$ & $0.274^{\mathrm{ns}}$ \\
\hline Chest pain in last 24 hours & 11 & $(78.5)$ & 1.50 & $0.37-3.84$ & $0.0001 * * *$ \\
\hline$\geq 3$ major risk factors & 4 & $(28.5)$ & 1.61 & $0.01-0.31$ & $0.020 *$ \\
\hline Current smoker & 3 & $(21.4)$ & 1.29 & $0.02-4.22$ & $0.006 * *$ \\
\hline Hypertension & 12 & $(85.7)$ & 1.51 & $0.00-0.14$ & $0.004 * *$ \\
\hline Diabetes & 9 & $(64.2)$ & 1.41 & $0.00-0.59$ & $0.027^{*}$ \\
\hline Dyslipidemia & 11 & $(78.5)$ & 1.22 & $0.01-5.09$ & $0.094^{\mathrm{ns}}$ \\
\hline Family history of IHD & 1 & $(7.1)$ & 1.12 & $0.01-7.80$ & $0.07^{\mathrm{ns}}$ \\
\hline Aspirin intake in last 7 days & 7 & $(50)$ & 2.11 & $0.59-9.19$ & $0.009 * *$ \\
\hline Prior Coronary artery disease & 2 & $(14.2)$ & 1.77 & $2.50-3.18$ & $0.003^{* *}$ \\
\hline Pulse $>100 / \mathrm{min}$ & 3 & $(21.4)$ & 2.49 & $1.81-24.86$ & $0.022 *$ \\
\hline Systolic $\mathrm{BP}<100 \mathrm{~mm} \mathrm{Hg}$ & 4 & $(28.5)$ & 2.02 & $0.01-2.63$ & $0.026^{*}$ \\
\hline Killip class II-IV & 7 & $(50)$ & 2.75 & $0.78-9.04$ & $0.002 * *$ \\
\hline ST deviation $\geq 0.5 \mathrm{~mm}$ & 6 & $(42.8)$ & 2.17 & $1.54-5.21$ & $0.001^{* *}$ \\
\hline Troponin/CKMB positive & 14 & $(100)$ & 1.71 & $0.13-1.73$ & $0.04^{*}$ \\
\hline
\end{tabular}

Table-II shows, $10.6 \%$ patients had major adverse cardiac events in UA/NSTEMI group and 11.6\% in STEMI group which was similar in both groups $(\mathrm{P}>0.05)$. In case of UA/NSTEMI death, recurrent MI and urgent revascularization were $7.5 \%, 1.5 \%$ \& $1.5 \%$ respectively. In case of STEMI all major adverse cardiac events were death (11.6\%).

Table III shows univariate analysis of potential 16 predictor variables selected from baseline characteristics. Out of them age $\geq 65$ years and chest pain in last 24 hours were significantly associated with MACE $(\mathrm{P}<0.001)$. Current smoker, hypertension, aspirin intake in last 7 days, prior coronary artery disease, Killip class II-IV and ST deviation $\geq 0.5 \mathrm{~mm}$ were associated with MACE $(\mathrm{P}<0.01)$. Presence of 3 or more major risk factors, diabetes, pulse $>100 / \mathrm{min}$, systolic $\mathrm{BP}<100 \mathrm{~mm}$ $\mathrm{Hg}$ and Troponin/CKMB positive were also significantly associated with MACE $(\mathrm{P}<0.05)$. Female sex, dyslipidemia and family history of IHD were not associated with MACE. 
Table-IV

Multivariate risk analysis of 30 days Major Adverse Cardiac Events of UA/NSTEMI. $(n=279)$

\begin{tabular}{lccc}
\hline Parameters & OR & $95 \%$ CI & P value \\
\hline Age e"65 years & 1.89 & $0.56-2.41$ & $0.005^{* *}$ \\
Female & 1.10 & $0.66-1.82$ & $0.004^{* *}$ \\
Chest pain in last 24 hours & 1.89 & $0.70-1.69$ & $0.009^{* *}$ \\
e”3 major risk factors & 1.51 & $0.16-1.64$ & $0.008^{* *}$ \\
Current smoker & 1.95 & $0.53-1.73$ & $0.009^{* *}$ \\
Hypertension & 1.67 & $0.27-1.44$ & $0.270^{\text {ns }}$ \\
Diabetes & 1.68 & $0.36-1.27$ & $0.022^{*}$ \\
Dyslipidemia & 1.99 & $0.58-1.69$ & $0.0001^{* * *}$ \\
Family history of IHD & 1.84 & $0.40-1.75$ & $0.633^{\text {ns }}$ \\
Aspirin intake in last 7 days & 1.93 & $0.55-1.56$ & $0.005^{* *}$ \\
Prior Coronary artery disease & 1.21 & $0.47-3.13$ & $0.028^{*}$ \\
Pulse $>$ 100/min & 1.19 & $0.35-4.03$ & $0.001^{* *}$ \\
Systolic BP<100mm Hg & 1.60 & $0.24-3.52$ & $0.002^{* *}$ \\
Killip class II-IV & 1.64 & $0.85-3.20$ & $0.001^{* *}$ \\
ST deviation e”0.5 mm & 2.11 & $0.08-3.10$ & $0.001^{* *}$ \\
Troponin/CKMB positive & 1.86 & $0.54-1.36$ & $0.015^{* *}$ \\
\hline
\end{tabular}

Table-V

Univariate risk analysis of 30 days Major Adverse Cardiac Events of STEMI. ( $n=279)$

\begin{tabular}{lccccc}
\hline Parameters & \multicolumn{2}{c}{ Overall $(\mathrm{n}=17)$} & OR & $95 \%$ CI & P value \\
& No. & $\%$ & & & \\
\hline Age $\geq 75$ years & 2 & $(11.7)$ & 1.94 & $0.13-2.79$ & $0.094^{*}$ \\
Female & 11 & $(64.7)$ & 0.15 & $0.03-0.89$ & $0.036^{*}$ \\
Weight $<67 \mathrm{~kg}$ & 10 & $(58.5)$ & 2.68 & $0.77-9.38$ & $0.012^{*}$ \\
Angina & 4 & $(23.5)$ & 1.52 & $0.01-0.52$ & $0.017^{*}$ \\
e”3 major risk factors & 13 & $(76.4)$ & 1.87 & $0.02-8.35$ & $0.030^{*}$ \\
Current smoker & 4 & $(23.5)$ & 1.43 & $0.06-3.12$ & $0.004^{*}$ \\
Hypertension & 10 & $(58.5)$ & 1.64 & $0.15-7.42$ & $0.003^{* *}$ \\
Diabetes & 8 & $(47.0)$ & 1.21 & $0.03-1.56$ & $0.012^{*}$ \\
Dyslipidemia & 8 & $(47.8)$ & 1.27 & $0.04-1.68$ & $0.161^{\mathrm{ns}}$ \\
Family history of IHD & 4 & $(23.5)$ & 2.53 & $0.07-3.78$ & $0.525^{\mathrm{ns}}$ \\
Aspirin intake in last 7 days & 3 & $(17.6)$ & 4.28 & $0.01-5.09$ & $0.0001^{* * *}$ \\
Pulse $>$ 100/min & 9 & $(52.9)$ & 1.91 & $0.22-3.74$ & $0.004^{* *}$ \\
Systolic BP $<100 m m$ Hg & 7 & $(41.1)$ & 1.44 & $0.11-2.79$ & $0.001^{* *}$ \\
Killip class II-IV & 11 & $(64.7)$ & 3.42 & $0.94-12.46$ & $0.042^{*}$ \\
Anterior MI or LBBB & 13 & $(76.4)$ & 2.11 & $0.42-3.19$ & $0.008^{* *}$ \\
Time to treatment $>$ 4 hours & 3 & $(17.6)$ & 1.19 & $0.72-1.21$ & $0.015^{*}$ \\
\hline
\end{tabular}

Table-IV shows multivariate analysis of potential 16 predictor variables selected from baseline characteristics. Out of them dyslipidemia was significantly associated with MACE $(\mathrm{P}<0.001)$. Risk factors those age $\geq 65$ years, female sex, chest pain in last 24 hours, 3 or more major risk factors, current smoker, aspirin intake in last 7 days, pulse $>100 /$ min, systolic BP $<100 \mathrm{~mm}$ Hg, Killip class II-IV, ST deviation $\geq 0.5 \mathrm{~mm}$ and Troponin/CKMB positive were significantly associated with MACE $(\mathrm{P}<0.01)$. Diabetes and prior 
Table-VI

Multivariate risk analysis of 30 days Major Adverse Cardiac Events of STEMI. ( $n=279)$

\begin{tabular}{lccc}
\hline Parameters & OR & $95 \%$ CI & P value \\
\hline Age $\geq 75$ years & 1.83 & $0.32-2.17$ & $0.001^{* *}$ \\
Female & 0.67 & $0.40-1.13$ & $0.013^{*}$ \\
Weight $<67 \mathrm{~kg}$ & 1.10 & $0.75-1.63$ & $0.005^{* *}$ \\
Angina & 1.77 & $0.30-1.96$ & $0.007^{* *}$ \\
$\geq 3$ major risk factors & 1.91 & $0.44-1.87$ & $0.032^{*}$ \\
Current smoker & 1.94 & $0.62-1.43$ & $0.785^{\mathrm{ns}}$ \\
Hypertension & 1.07 & $0.67-1.72$ & $0.770^{\mathrm{ns}}$ \\
Diabetes & 1.73 & $0.39-1.73$ & $0.007^{*}$ \\
Dyslipidemia & 1.92 & $0.59-1.43$ & $0.706^{\mathrm{ns}}$ \\
Family history of IHD & 1.86 & $0.50-1.48$ & $0.006^{* *}$ \\
Aspirin intake in last 7 days & 1.50 & $0.48-4.75$ & $0.001^{* *}$ \\
Pulse $>100 /$ min & 1.04 & $0.65-1.67$ & $0.006^{* *}$ \\
Systolic BP $<100 \mathrm{~mm}$ Hg & 1.95 & $0.57-3.57$ & $0.0001^{* * *}$ \\
Killip class II-IV & 1.30 & $0.82-2.04$ & $0.046^{*}$ \\
Anterior MI or LBBB & 2.18 & $0.34-4.64$ & $0.001^{* *}$ \\
Time to treatment $>4$ hours & 1.15 & $0.05-1.95$ & $0.010^{*}$ \\
\hline
\end{tabular}

coronary artery disease were also associated with adverse outcome $(\mathrm{P}<0.05)$. Hypertension and family history of IHD were not associated with adverse outcome.

Table-V shows univariate analysis of potential 16 predictor variables selected from baseline characteristics of STEMI group. Out of them aspirin intake in last 7 days was significantly associated with MACE $(\mathrm{P}<0.001)$. Hypertension, pulse $>100 /$ min, systolic $\mathrm{BP}<100 \mathrm{~mm} \mathrm{Hg}$ and anterior MI or LBBB were significantly associated with MACE $(\mathrm{P}<0.01)$. Age $\geq 75$ years, weight $<67 \mathrm{~kg}$, angina, 3 or more major risk factors, current smoker, diabetes, Killip class II-IV, and time to treatment $>4$ hours were also associated with MACE $(\mathrm{P}<0.05)$. Dyslipidemia and family history of IHD were not associated with MACE. Female sex was not a significant risk factor $(\mathrm{P}<0.05)$.

Table-VI shows multivariate analysis of potential 16 predictor variables selected from baseline characteristics of STEMI group. Age $\geq 75$ years, weight $<67 \mathrm{~kg}$, angina, family history of IHD, aspirin intake in last 7 days, pulse $>100$ /min, and anterior MI or LBBB were associated with MACE $(\mathrm{P}<0.01) .3$ or more major risk factors, diabetes, Killip class II-IV and time to treatment $>4$ hours were also associated with MACE $(\mathrm{P}<0.05)$. Current smoker, hypertension and dyslipidemia were not associated with MACE. Female sex was not a significant risk factor $(\mathrm{P}<0.05)$.

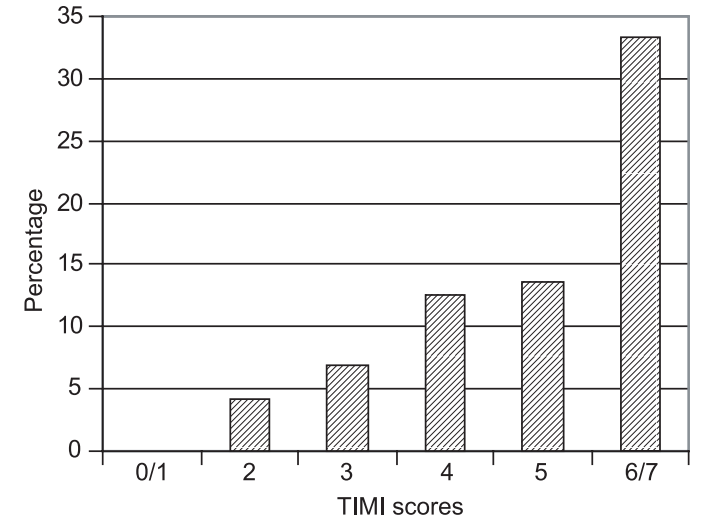

Fig-1: Major adverse cardiac events by 14/30 days in UA/NSTEMI group.

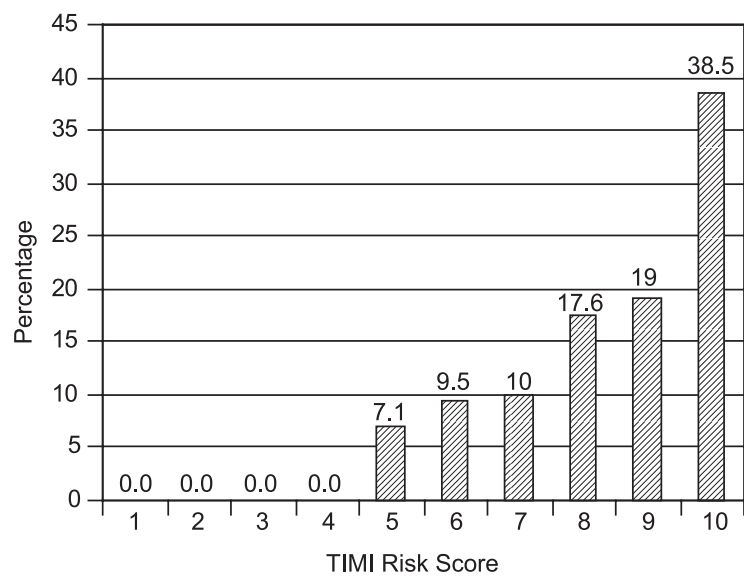

Fig-2: Major adverse cardiac events by 14/30 days in STEMI group. 


\section{Discussion:}

MACE of TIMI risk scores in this study at 14/30 days for UA/NSTEMI group 0/1, 2, 3, 4, 5 and 6/7 showed $0 \%, 4.2 \% 6.9 \%, 12.5 \%, 13.6 \%$ and $33.3 \%$ patients respectively. No difference observed between 14 and 30 days adverse outcome. Lowest rate of MACE was observed in 0/1 score and highest MACE in score 6/7. Increasing risk score was associated with increased risk of events ( $P$ trend $<0.01$ ).

In TIMI 11B trial MACE increased significantly as the TIMI score increased in UA/NSTEMI group (Antman et al. 2000). In ESSENCE trial (Antman et al. 2000), MACE increased significantly as the TIMI score increasedin UA/ NSTEMI patients through 14 days in enoxaparin group. In PRISM-PLUS trial (Sabatine et al. 2003), MACE increased as TIMI risk scores for UA/NSTEMI group increased through 14 days. In TACTICS trial (Cannon et al. 2000), MACE increased significantly as the TIMI score increased in UA/NSTEMI group respectively through 6 months. Study conducted by Bartholomew et al. (2001) found MACE increased significantly as the TIMI score increased in UA/NSTEMI group respectively through 30 days. This study revealed that MACE of TIMI $0-5$ group was relatively lower than all other study groups. MACE of TIMI 6/7 group was lower than unfractionated heparin group in TIMI 11B trial, unfractionated heparin group in ESSENCE trial and study conducted by Bartholomew et al. (2001) but higher than enoxaparin group in TIMI 11B trial, enoxaparin group on ESSENCE trial, PRISM-PLUS and TACTICS-TIMI 18 trial. This difference might be due to delayed arrival of patient in hospital, lack of early intervention and probably small sample size of study.

MACE of TIMI risk scores at 14/30 day in this study for STEMI group 0, 1, 2, 3, 4, 5, 6, 7, 8 and more than 8 showed $0 \%, 0 \% 0 \%, 0 \%, 7.1 \%, 9.5 \% 10 \%, 17.6 \%, 19 \%$ and $38.5 \%$ patients respectively. No difference observed between 14 and 30 days adverse outcome. Lowest MACE observed with in 0-3 score and highest in score more than 8.

Morrow et al. (2000) conducted a study involving 15078 patient presented with STEMI. After 30 days study revealed 6.7\% patient died. Study showed MACE was increased significantly as the TIMI risk score was increased. Antman et al. (1996) revealed strong association with 30 days mortality of patient treated with fibrinolytics for STEMI. This study showed that outcome was relatively lower in 08 TIMI group but were higher in group $>8$ than other study group. This difference might be due to delayed arrival of patient in hospital, lack of early intervention and probably small sample size of study.

\section{Conclusion:}

We tested risk stratification strategies on a group of ACS patient. The TIMI risk score and TIMI risk index may be readily applied as a prognostic tool at the bed side of hospital and may forecast the major adverse prognostic information. This risk management tool is likely to be clinically useful in the triage and management of patients eligible for fibrinolytic therapy as well as early revascularization. TIMI risk score and TIMI risk index for UA/NSTEMI \& STEMI may be readily applied at the bedside at the time of hospital presentation. Patients with higher TIMI risk score \& TIMI risk index at presentation needs early invasive management to reduce MACE.

Although most of the results of this study have come up with the statistically significant findings, there are some facts to be considered which might affect the result. These are,

- Limited number of subjects.

- Short follow up period.

\section{Reference:}

1. Haque SA, Detection of left ventricular diastolic dysfunction in first acute myocardial infarction by Doppler Echocardiography, MD Thesis, BSMMU, Dhaka, 2001.

2. Norris RM, Brandt PWT, Caughy DE, et al. A new coronary prognostic index. the lancet 1969; vol. 1, 8 February: 274-78.

3. Fuster V, Badimon L, Badimon JJ, Chesebro JH, The pathogenesis of coronary artery disease and the acute coronary syndromes (Part 2). N Engl J Med. 1992; 326: 310-18.

4. Antman EM, Cohen M, Bernink PJ, et al. The TIMI Risk Score for Unstable Angina/Non-ST Elevation MI: a Method for Prognostication and Therapeutic Decision Making. JAMA 2000; 284: 836-42.

5. Morrow DA, Antman EM, Charlesworth A, et al. TIMI Risk Score for ST-Elevation Myocardial Infarction: A Convenient, Bedside, Clinical Score for Risk Assessment at Presentation : An Intravenous nPA for Treatment of Infarcting Myocardium Early II Trial Substudy Circulation 2000, 102:2031-37

6. Sabatine MS and Antman EM. The thrombolysis in myocardial infarction risk score in unstable angina/non-ST-segment elevation myocardial infarction J. Am. Coll. Cardio. 2003; 41: 895-955

7. Cohen M, Demers C, Gurfinkel EP, et al. A comparison of low molecular weight heparin with unfractionated heparin for unstable coronary artery disease. N Engl J Med 1997; 337:447-52.

8. Antman EM, McCabe CH, Gurfinkel EP, et al. Enoxaparin prevents death and cardiac ischemic events in unstable angina/ non-Qwave myocardial infarction: results of the Thrombolysis In Myocardial Infarction (TIMI) 11B trial. Circulation 1999; 100: 15931601.

9. Cannon CP, Weintraub WS, Demopoulos LA, et al. Comparison of early invasive and conservative strategies in patients with unstable coronary syndromes treated with the glycoprotein IIb/IIIa inhibitor tirofiban. NEngl J Med 2001; 334:1879-87.

10. Newby LK, Calief MR, Guerci A. et al. Early discharge in the thrombolytic era: an analysis of criteria for uncomplicated infarction from the global infarctionfrom the global utilization of streptokinase and t-PA for occluded coronary arteries (GUSTO) trial. J am Coll card 1996; 27: 625-32. 